Library Acquisitions: Practice and Theory, (Winter 1992), v.16, i.4, pp.420-421.

ISSN: 0364-6408

http://www.sciencedirect.com/science/journal/03646408

http://www.sciencedirect.com/science/article/pii/036464089290018N

http://dx.doi.org/10.1016/0364-6408(92)90018-N

Copyright () 1992 Published by Elsevier Ltd. All rights reserved.

\title{
ALCTS SS Research Libraries Discussion Group, January 25, 1992
}

\section{Carol Pitts Hawks}

1992 Chair Mary Bushing of Montana State University opened the meeting with the introduction of guest speaker, Beth TenHave of Michigan State University (MSU). The topic_-"Exploring Organizational Models for Serials Processing"—was selected "to generate discussion about the changing nature of the processes, work flow, and personnel necessary and appropriate for serial processing in the nineties and beyond."

Michigan State is an ARL library using the Innovative Interfaces' INNOVACQ system for acquisitions and serials control. The entire Libraries' staff totals 204 individuals including 69 in technical services. In FY91, the materials budget was approximately $\$ 4$ million with $\$ 2.6$ million expended on serials. In FY91, 16,885 subscriptions were received throughout the library system. Central technical services excluding two branch libraries and government documents processed 181,824 serial pieces through check-in. Serial titles cataloged in FY91 totaled 2,255.

TenHave identified four trends leading to the examination of the structure of technical services. The first trend related to personnel and staffing changes. Specifically, five of eleven technical services librarian managers were lost. Skilled staff was being under utilized. Lack of staff turnover resulted in little flexibility in reorganizing. The second trend concerned the funding of the library materials budget. Although the budget had not been cut, it had not been growing fast enough to meet price increases either. As a result, the mix of materials purchased had been shifting from monographs to serials.

The third trend was found in the university administration's Nineties Strategy. This planning process began a refocusing of resources in 1987. The 1990s theme was "doing more with less." The fourth trend focused on automation efforts. Although MSU was one of the first libraries to use INNOVACQ serials check-in, subsequent automation efforts had stagnated.

Over the course of the past two years, MSU has been examining its organizational structure for technical services and recommending specific changes to the library administration. A planning team with broad representation was appointed to develop an action plan with a timeline for implementation. This team included seven professional staff and seven parapro-fessional staff. Public services staff were included as well. Individual subgroups were appointed to address specific issues and each forwarded a report to the planning team. For example, the work flow subgroup was charged with documenting all work flows, making recommendations, and submitting a final report.

In mid-1991, a design team was appointed to implement a reorganization of technical services, A preliminary report was issued in August 1991 proposing three possible models. After 
further discussion, a final report proposing two models was submitted. The model currently being implemented is not exactly what the design team recommended. For example, a coordinator for cataloging was recommended by the team but eliminated by the library administration in actual implementation.

The new organization eliminated format separation between monographs and serials. Due to the changing expenditure pattern from monographs to serials, more staff had to become knowledgeable about serials. Two acquisitions units were combined into one unit including all bibliographic searching for all formats. Receiving and Accounting were combined into a single unit. All items added to the collection whether through traditional order/receipt, approval, or gift are received through this unit. An acquisitions coordinator oversees these two units.

As mentioned earlier, the cataloging teams are not overseen by a cataloging coordinator as recommended. There are three cataloging teams, a database management team, and a principal cataloger. A LA1 in each team will do precatalog searching. Each team does general cataloging and has one specialized area such as CJK, Africana, or Special Collections under its jurisdiction. There are original catalogers on each team as well. Three of the teams (two in Acquisitions and the Database Management Team in Cataloging) will have an assistant team manager due to the size of the team.

Staff reaction has been a major factor in the success of this reorganization. Staff had become bored because few opportunities existed for advancement. They were eager to learn new things and have increased responsibility. However, due to membership in the union, the reorganization had to handled very carefully. Nevertheless, staff reaction has been very positive.

The Assistant Director for Technical Services conducted two rounds of individual sessions with each of the 69 staff members in technical services. The design team was instructed to take at least six weeks to discuss their proposal with staff and consider their concerns. Ultimately, the Assistant Director will assign individuals to the various teams.

Reclassification has been an inevitable necessity resulting in fewer entry-level positions. Due to the increase in repetitive stress injuries, MSU is considering more part-time options for employment. The greatest difficulty has been in filling the cataloging team manager positions. Many of the catalogers did not want to supervise, evaluate, etc. but, instead, were more interested in maintaining their subject specializations. Another major hurdle has been the de-mystification of serials and the opening of these processes and procedures to everyone. This has been the hardest to accept for the professional staff.

TenHave ended her presentation with several reality issues. This process was very labor-intensive and inevitably was based in financial and organizational realities. In addition, staff should be involved as much as possible. 